\title{
The Permeability of Waste Fiber Recycled Concrete
}

\author{
Jinghai ZHOU *, Tianbei KANG, Fengchi WANG
}

\author{
School of Civil Engineering, Shenyang Jianzhu University, Shenyang, China \\ crossref http://dx.doi.org/10.5755/j01.ms.26.2.21143
}

Received 04 July 2018; accepted 14 November 2018

\begin{abstract}
Permeability is one of the major performances for recycled aggregate concrete, which affects the durability and service life of concrete structures. In most cases, the main factor affecting the permeability of recycled aggregate concrete is the pore structure. Considering water-cement ratio, replacement rate of recycled aggregates, waste fiber length, and volume fraction of waste fibers as the design variables, pore structure and gas permeability were studied experimentally. In addition, fractal theory was here used to assess the pore structure of waste fiber recycled concrete and study the effects of pore structure on permeability. The results showed that the pore size distribution had a small impact on the permeability with the water-cement ratio and replacement rate of recycled aggregates increasing. The fractal dimension can be used to describe the complexity of the pore structure quantitatively. There is an obvious linear relationship between fractal dimension and gas permeability. The larger the pore volume fractal dimension, the better the impermeability of waste fiber recycled concrete.
\end{abstract}

Keywords: recycled concrete, waste fibers, pore structure, fractal dimension, permeability.

\section{INTRODUCTION}

The application of recycled concrete is one of the measures to develop green architecture and to realize the coordinated development of the construction industry, natural resources, and environment. Recycled concrete not only solves the problem of construction waste but also can reduce the exploitation of natural stone, thus slowing the deterioration of the ecological environment [1,2]. Studies have shown that the mechanical property and durability of recycled concrete are inferior to ordinary concrete [3-5], which restricts the popularization and application of recycled concrete in practical engineering to a certain extent. The addition of fiber can improve the physical properties of recycled concrete and act as a bridging role when cracks occur in the concrete matrix $[6,7]$. The additions of various kinds of fiber can improve the mechanical properties and control the cracking processes of the recycled concrete $[8,9]$. The mechanical properties of recycled concrete components can be optimized by the addition of waste fibers in a reasonable amount [10-12]. Waste fiber recycled concrete is a type of green concrete that can realize the reuse of waste fibers and construction wastes. It not only promotes the application of recycled concrete but is also essential for the protection of the ecological environment.

Durability is one of the important properties that must be studied, because it has a critical influence on the service life of the concrete structure. Mehta et al. [13] pointed out that the greatest impact on the durability of concrete was permeability. Permeability of concrete is the ability of gas penetration, liquid diffusion or ion migration when in the action of pressure, chemical potential or electric field, and the ability of erosion resistance of various media [14]. Studies have shown that the applications of recycled aggregates in concrete exist in the problem of durability. According to the experimental results of Kou et al. [15], the impermeability of recycled concrete was lower than that of ordinary concrete with the same ratio. Kwan et al. [16] reported that recycled aggregate concrete exhibited low intrinsic permeability when $80 \%$ of the total coarse aggregate was replaced by recycled coarse aggregate. At the same time, Evangelista et al. [17] pointed out that water permeability, capillary absorption, and chloride diffusion of concrete increased with the increase of the replacement ratio of fine recycled aggregate.

Permeability is one of the basic properties of porous materials, reflecting the size, quantity, distribution, and connectivity of the pores and channels in the material. There is an intuitionistic relationship between permeability and pore size distribution in concrete $[18-20]$. The incorporation of polypropylene fibers increased porosity and permeability of conventional concrete were reported in reference [21], polypropylene fibers ranged from 0 to $0.1 \%$, $0.3 \%$, and $0.5 \%$ by volume of concrete. The permeability of recycled concrete showed a close correlation with porosity, air diffusivity, and water absorption [22]. The pore structure of concrete can be used to predict the performance of concrete in various ways, including the permeability of the concrete [23].

The pore structure of concrete is complicated and disordered, and traditional parameters cannot describe its complexity. The fractal theory proposed by Mandelbrot [24] is an important branch of nonlinear science, which is used to describe irregular phenomena and behaviors in nature. Fractal theory quantitatively represents the complexity of material as the fractal dimension. Concrete exhibits a series of fractal characteristics, both in the material itself and in the course of its work [25-27]. Pape et al. [28] indicated that the permeability information was theoretically founded

\footnotetext{
${ }^{*}$ Corresponding author. Tel. +8613904334615 .

E-mail address: jinghaiz@qq.com (J.H. Zhou)
} 
on a fractal model for the internal structure of a porous medium. The fractal model was sufficiently flexible and applicable over a wide range of porosities. In summary, only a few studies of the pore structure and permeability of fiber recycled concrete have been performed.

In this study, the pore structure and permeability of waste fiber recycled concrete were studied by mercury intrusion porosimetry (MIP) test, scanning electron microscope (SEM) test and gas permeability test. The pore structure of waste fiber recycled concrete and the relationship between the pore structure and permeability were analyzed by fractal theory. The research results provide a theoretical basis for the study of durability of waste fiber recycled concrete.

\section{EXPERIMENTAL}

\subsection{Materials}

The cement used in this study was ordinary Portland cement (P.O42.5). The fine aggregate was natural river sand with a fineness modulus of 2.7. There were two kinds of coarse aggregate, one of which was natural aggregates (RA) and the other was recycled aggregates (CA). The recycled aggregates were obtained from abandoned reinforced concrete beams that were 1 year in age. The properties of the coarse aggregates were tested according to GB/T 50081 (Chinese standard) and the physical properties are shown in Table 1. The average compressive strength of the original concrete was $40 \mathrm{MPa}$. Waste fibers came from abandoned carpets, the chemical composition of the waste fibers was polypropylene, physical properties are listed in Table 1 and the preparation of waste fibers are described in Fig. 1.

Table 1. Properties of aggregates and waste fibers

\begin{tabular}{|l|c|c|c|}
\hline \multicolumn{1}{|c|}{ Properties } & RA & NA & Waste fibers \\
\hline Density, $\mathrm{kg} / \mathrm{m}^{3}$ & 2461 & 2690 & 910 \\
\hline Crushing index, \% & 17 & 6.4 & - \\
\hline Water absorption, \% & 4.18 & 1.12 & $<0.1$ \\
\hline Particle size, $\mathrm{mm}$ & $5 \sim 25$ & $5 \sim 25$ & - \\
\hline
\end{tabular}

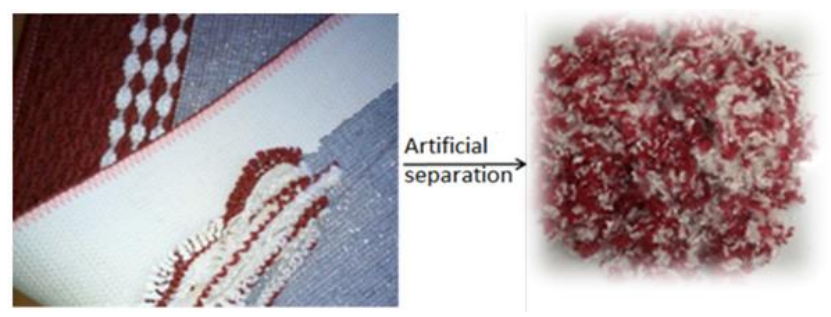

Fig. 1. Preparation of waste fibers

\subsection{Mixture proportions}

10 cubic specimens $(150 \times 150 \times 150 \mathrm{~mm})$ were prepared for the test. The design variables of the experiment were water-cement ratio $(0.45,0.5,0.55)$, replacement rate of recycled aggregates $(0 \%, 50 \%, 100 \%)$, waste fiber length $(12 \mathrm{~mm}, 19 \mathrm{~mm}, 30 \mathrm{~mm})$ and volume percent $(0 \%$, $0.08 \%, 0.12 \%, 0.16 \%)$. The water used in the experiment was divided into two parts: free water and additional water. As shown in Table 2 and references $[2,5,10]$. The function of free water was hydration reaction with cement, while the additional water was to reduce the influence of the large water absorption of recycled coarse aggregates on the compressive strength. The mixture proportions of the waste fiber recycled concrete and compressive strength are given in Table 2. Compressive strength was determined according to the GB/T 50081 (Chinese Standard).

\subsection{Methods}

\subsubsection{Specimen preparation}

To prepare the waste fiber recycled concrete, aggregates (natural gravels and recycled coarse aggregates) and waste fibers were mixed for $2 \mathrm{~min}$ in a concrete blender, and then the cement and water were added and stirred at low speed for 2-3 min to achieve good workability. The preparation method made the waste fibers disperse uniformly to ensure the uniformity and strength of waste fiber recycled concrete [10]. All the specimens were cured for $28 \mathrm{~d}$ in the curing room, where the relative humidity was no less than $95 \%$ and the temperature was $20 \pm 2{ }^{\circ} \mathrm{C}$.

\subsubsection{Mercury intrusion porosimetry (MIP) test}

There are several methods that are usually used to assess the pore structure of the concrete [29]. The MIP technique is simple, quick to perform, and covers a wide range of pore diameters. The porosity of recycled concrete is different from that of ordinary concrete due to the adhered mortar present in recycled aggregates [30]. Many studies [31-34] have used the MIP technique to investigate the influence of recycled aggregates on the pore size distribution of concrete.

In this study, the Micrometrics Auto Pore IV 9500 manufactured by Micron Instruments was selected for the pore structure measurement. Maximum pressure value was $228 \mathrm{MPa}$, and the measured pore size ranged from $5 \mathrm{~nm}$ to $360.000 \mathrm{~nm}$. The test of MIP was conducted according to ISO 15901-1. Specimen size for MIP test was 3-5 mm, and two samples were taken for parallel experiments in each group. In order to reduce the effect of heterogeneity of recycled concrete, the mortar samples were tested, and the sampling method from references [31, 32] was used. Each specimen was placed in a jar and hydration was stopped with absolute alcohol. The samples were dried in a drying oven at $105^{\circ} \mathrm{C}$ for $24 \mathrm{~h}$ and cooled to room temperature.

\subsubsection{Scanning electron microscope (SEM) test}

SEM tests were carried out by $\mathrm{S}-4800$ scanning electron microscope. All specimens were taken from the center of the cube test blocks.

\subsubsection{Permeability test}

The Torrent Tester Breathable Tester (see Fig. 2) was used to create a vacuum environment on top of $150 \times 150 \times 150 \mathrm{~mm}$ cubic specimens. The gas flow on the surface of the specimen enters the internal vacuum plug, which ensures the tightness of the test sample surface by maintaining equal pressure inside and outside the two vacuum plugs. The gas permeability coefficient $K_{\mathrm{T}}$, and the gas penetration depth $L$, of the concrete were determined by testing the pressure difference $\Delta p$, before and after the permeability of the concrete sample. 
Table 2. Concrete mixes and compressive strength

\begin{tabular}{|l|c|c|c|c|c|c|c|c|c|c|}
\hline \multicolumn{1}{|c|}{ Series } & SJ-1 & SJ-2 & SJ-3 & SJ-4 & SJ-5 & SJ-6 & SJ-7 & SJ-8 & SJ-9 & SJ-10 \\
\hline Water-cement ratio( W/C) & 0.5 & 0.45 & 0.55 & 0.5 & 0.5 & 0.5 & 0.5 & 0.5 & 0.5 & 0.5 \\
\hline Recycled aggregate replacement rate, \% (VR) & 50 & 50 & 50 & 0 & 100 & 50 & 50 & 50 & 50 & 50 \\
\hline Waste fiber length, mm (Lf) & 19 & 19 & 19 & 19 & 19 & 12 & 30 & 0 & 19 & 19 \\
\hline Volume fraction of waste fibers, \% (Vf) & 0.08 & 0.08 & 0.08 & 0.08 & 0.08 & 0.08 & 0.08 & 0 & 0.12 & 0.16 \\
\hline Cement, kg/m & 390 & 433 & 355 & 390 & 390 & 390 & 390 & 390 & 390 & 390 \\
\hline Sand, $\mathrm{kg} / \mathrm{m}^{3}$ & 709 & 674 & 741 & 709 & 709 & 709 & 709 & 709 & 709 & 709 \\
\hline Nature aggregate, $\mathrm{kg} / \mathrm{m}^{3}$ & 578 & 574 & 580 & 1156 & 0 & 578 & 578 & 578 & 578 & 578 \\
\hline Recycled aggregate, $\mathrm{kg} / \mathrm{m}^{3}$ & 578 & 574 & 580 & 0 & 1156 & 578 & 578 & 578 & 578 & 578 \\
\hline Water, $\mathrm{kg} / \mathrm{m}^{3}$ & 205 & 205 & 205 & 195 & 215 & 205 & 205 & 205 & 205 & 205 \\
\hline Compressive strength, MPa & 40.1 & 44 & 35.8 & 42.6 & 38.6 & 38.5 & 42.7 & 37.5 & 43.0 & 42.5 \\
\hline
\end{tabular}

The permeability test was carried out according to GB/T 50081 (Chinese Standard).

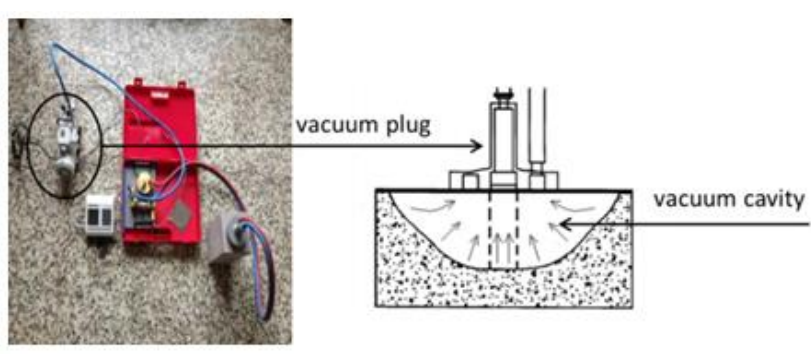

Fig. 2. Torrent tester breathable tester

\section{RESULTS AND DISCUSSION}

\subsection{Pore structure of waste fiber recycled concrete}

According to the research results of $\mathrm{Wu}$ [19], the pore structure of waste fiber recycled concrete is divided into four categories: harmless pore $(r \leq 20 \mathrm{~nm})$, less harmful pore $(20<r \leq 100 \mathrm{~nm})$, harmful pore $(100<r \leq 200 \mathrm{~nm})$, and more harmful pore $(r>200 \mathrm{~nm})$. Mehta [13] pointed out that pores of $r>100 \mathrm{~nm}$ have the greatest impact on the permeability of concrete. These pores are larger diameter capillary pores and are mainly formed by insufficient vibration or the process of hydration, which are controlled pores. The pores of $r \leq 100 \mathrm{~nm}$ are capillary pores and micro-porous, which are unevenly distributed under each aperture, due to the complexity of the microcosmic reaction process. The pore size distribution of waste fiber recycled concrete is listed in Table 3.

Table 3. Pore size distribution

\begin{tabular}{|c|c|c|c|c|}
\hline \multirow{2}{*}{$\begin{array}{c}\text { Serie } \\
\mathrm{s}\end{array}$} & \multicolumn{4}{|c|}{ Aperture distribution, \% } \\
\cline { 2 - 5 } & $\begin{array}{c}r \leq 20 \mathrm{n} \\
\mathrm{m}\end{array}$ & $\begin{array}{c}20<r \leq 100 \mathrm{n} \\
\mathrm{m}\end{array}$ & $\begin{array}{c}100<r \leq 200 \mathrm{n} \\
\mathrm{m}\end{array}$ & $\begin{array}{c}r>200 \mathrm{n} \\
\mathrm{m}\end{array}$ \\
\hline SJ-1 & 15.94 & 29.22 & 5.29 & 49.55 \\
\hline SJ-2 & 22.87 & 45.59 & 4.37 & 27.17 \\
\hline SJ-3 & 11.14 & 28.55 & 5.75 & 54.56 \\
\hline SJ-4 & 18.58 & 40.87 & 3.73 & 36.82 \\
\hline SJ-5 & 11.51 & 26.47 & 8.38 & 53.64 \\
\hline SJ-6 & 14.94 & 27.60 & 6.95 & 50.51 \\
\hline SJ-7 & 17.58 & 37.33 & 5.25 & 39.84 \\
\hline SJ-8 & 11.32 & 24.82 & 7.56 & 56.30 \\
\hline SJ-9 & 18.36 & 40.05 & 3.43 & 38.16 \\
\hline SJ-10 & 16.22 & 31.35 & 3.63 & 48.80 \\
\hline
\end{tabular}

It can be seen from Table 3 that with the increase of water-cement ratio and replacement rate of recycled aggregates, the waste fiber length decreased, and the pore size distribution had less influence on the permeability $(r \leq 100)$. With the increase of fiber volume fraction, the pore size distribution law of the pores $r \leq 100$ increased first and then decreased, which indicates that there is an optimum fiber volume fraction of waste fiber recycled concrete. The mercury increment and the cumulative amount of mercury are presented in Fig. 3.

Table 3 and Fig. 3 a show that the water-cement ratio has the greatest influence on the aperture. In Fig. $3 \mathrm{~b}$, the accumulated mercury of SJ-3 is the largest and the proportion of pores $r>100 \mathrm{~nm}$ is $60.33 \%$, which is 1.92 and 1.10 times those of the mixtures with water-cement ratios of 0.45 and 0.5 , respectively. Due to the high hydration degree of cement particles in concrete with larger water-cement ratio, the pore size of concrete increases, thus increasing the probability of the harmful pore and the more harmful pore.

The recycled coarse aggregates are detrimental to the pore structure due to its initial damage. In Table 3 and Fig. 3 b, the cumulative mercury amount of SJ-5 with recycled aggregate replacement rate of $100 \%$ was the largest and the pores of $r>100 \mathrm{~nm}$ accounted for $62.02 \%$.

According to Table 3 and Fig. $3 \mathrm{c}$, the cumulative amount of mercury decreased as the length of waste fibers increased. The addition of fibers can refine the harmful pore and the more harmful pore in waste fiber recycled concrete to a certain extent.

With the increase of the volume fraction of waste fibers, the cumulative amount of mercury decreased first and then increased (see Table 3 and Fig. 3 d). The optimum substitution content of waste fiber in this study was $0.12 \%$, which is the same conclusion as in references $[10,11]$. The mercury cumulative amount of SJ-10 was nearly 1.36 times that of SJ-9. Because of the excessive amount of fibers, dispersion was difficult during the preparation of concrete and thus weak areas formed. The volume fraction of waste fiber had a greater effect on the pore structure than the fiber length.

In this study, Menger's model [24] was employed to analyze the fractal characteristics of the pore structures in waste fiber recycled concrete cement pastes. The fractal dimension $D$ is related to the complexity of the pore structure in the spatial distribution. In general, higher $D$ means more complex volume micro-detail, otherwise, the pore structures are relatively simple. At the same time, the larger the fractal dimension, the better the density of concrete and the higher the performance. 


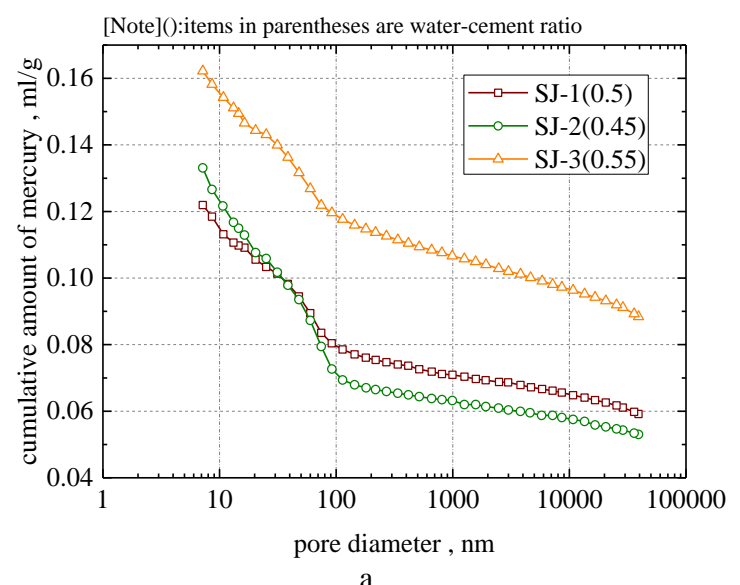

[Note]():items in parentheses are recycled aggregate replacement rate

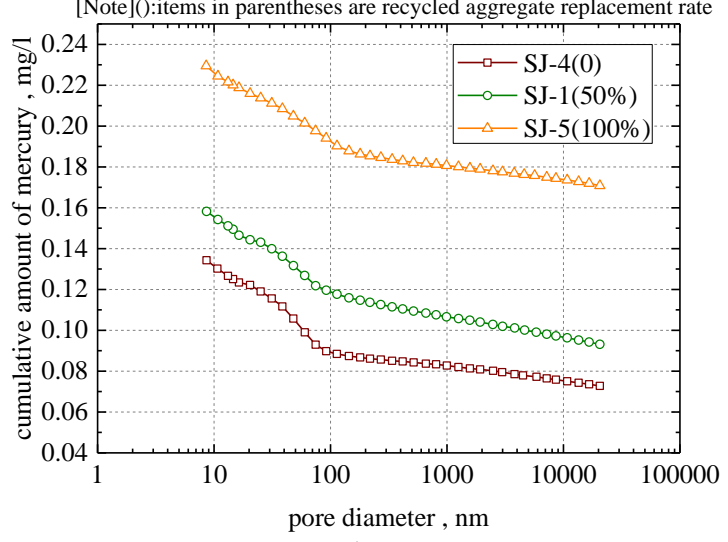

$\mathrm{b}$
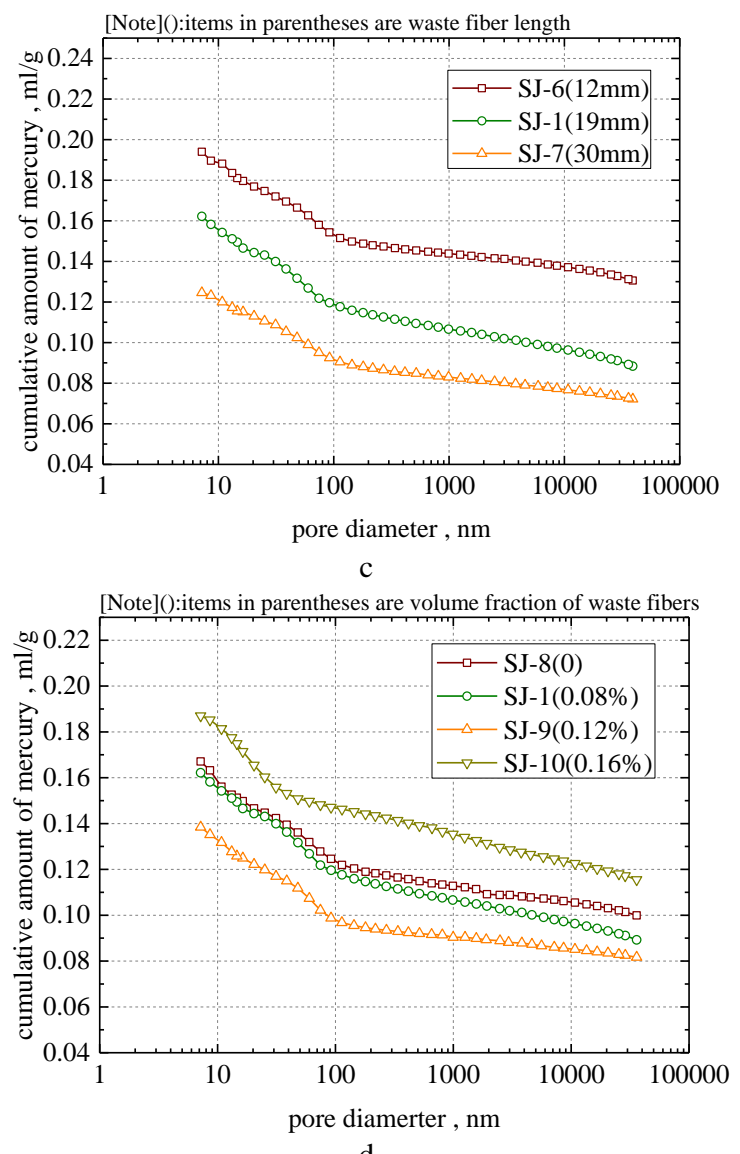

d

Fig. 3. Cumulative amount of mercury of specimens: a-watercement ratio; $b$-replacement rate of recycled aggregates; $\mathrm{c}$-waste fiber length; $\mathrm{d}$-waste fiber volume content
The fractal dimension $D$ can be obtained Eq. 1 [24]

$$
D=3-\lg (d V / d r) / \lg (d r),
$$

Where $V$ is the volume of mercury intake at all levels of pressure, $r$ is the corresponding aperture. According to the date of MIP test, there is a liner relationship between $\log (\mathrm{d} V / \mathrm{d} r)$ and $\log (\mathrm{d} r)$, moreover, the correlation $\mathrm{R}$ is not less than 0.96. The fractal dimension of pore volume is obtained through the slope of the straight line. The fractal dimensions $D$ of the specimens are presented in Fig. 4.

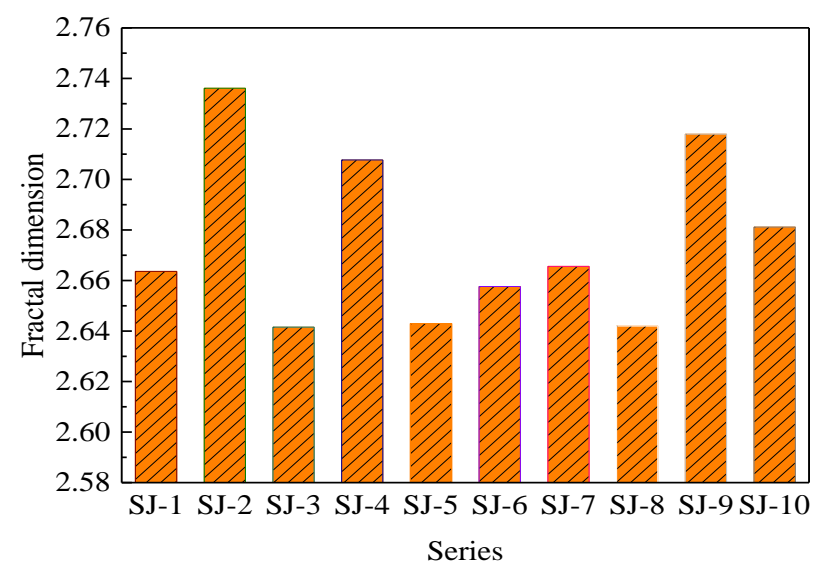

Fig. 4. The pore volume fractal dimension

\subsection{Permeability of waste fiber recycled concrete}

Fig. 5 shows the curve of gas permeability coefficient $K_{\mathrm{T}}$ and gas penetration depth $L$ varying with the design variables. The gas permeability coefficient is directly proportional to the gas penetration depth, and one of them can be used to judge the permeability of waste fiber recycled concrete.

In Fig. 5 a, with the decrease of water-cement ratio, the gas permeability coefficient $K_{T}$ and gas penetration depth $L$ of waste fiber recycled concrete show a downward trend. The increase in cement content was accompanied by a decrease in water-cement ratio. The $\mathrm{Ca}(\mathrm{OH})_{2}$ in the hydration product can fill the pores and increase roughness. In addition, the low water-cement ratio can improve the strength of recycled concrete, narrow the elastic modulus gap between the cement and recycled aggregate, and the recycled concrete will be more compact.

As is shown, gas permeability coefficient $K_{T}$ and gas penetration depth $L$ rose with the increase of the amount of recycled aggregates (see Fig. 5 b and Fig. 6). The old mortar was attached to the recycled aggregate and formed an interface transition zone with the new cement stone. From the SEM test of recycled concrete (see Fig. 6), it can be seen that the $\mathrm{Ca}(\mathrm{OH})_{2}$ in the interface transition zone is perpendicular to the surface of the aggregate and grows outward, and the concrete can see obvious micro-cracks at the interface between the aggregate and the cement before the load is loaded, and the crack first appears at the interface and is easily extend along the interface transition zone to the cement base. This interface transition zone became the gas permeation channel due to poor adhesion. Therefore, addition of recycled aggregate reduces the permeability of recycled fiber concrete. 


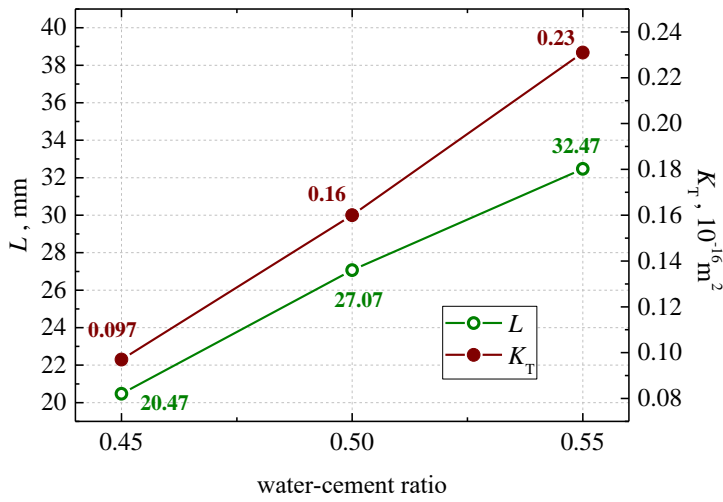

a

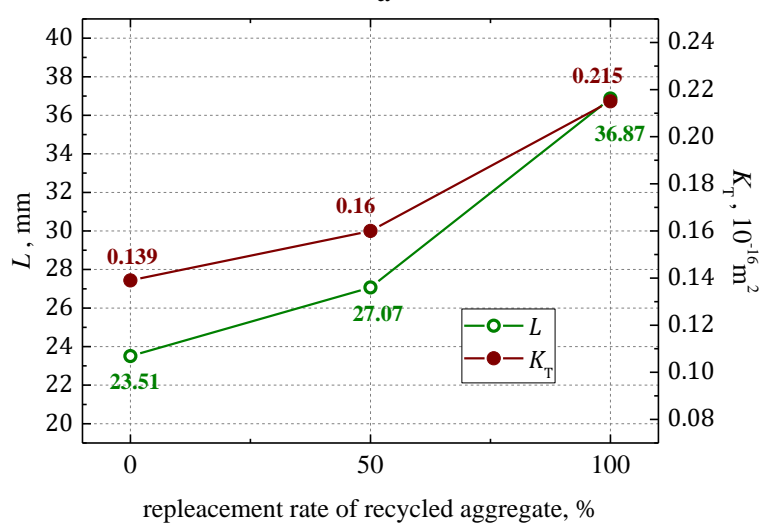

b

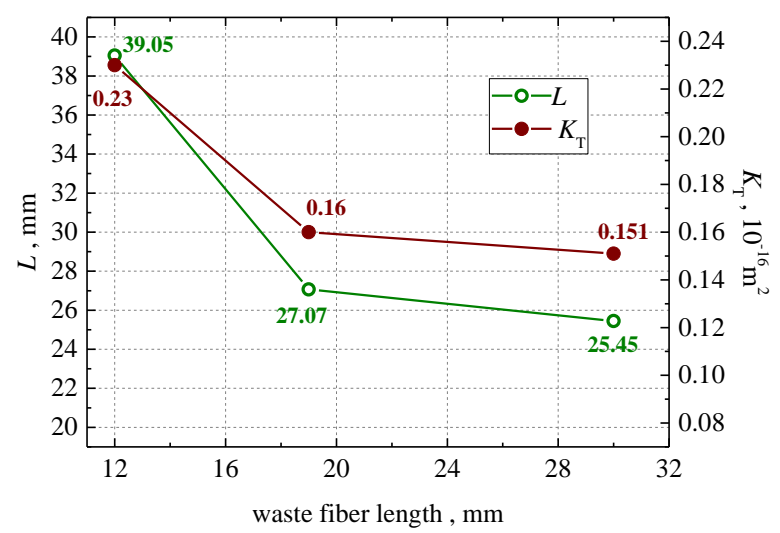

c

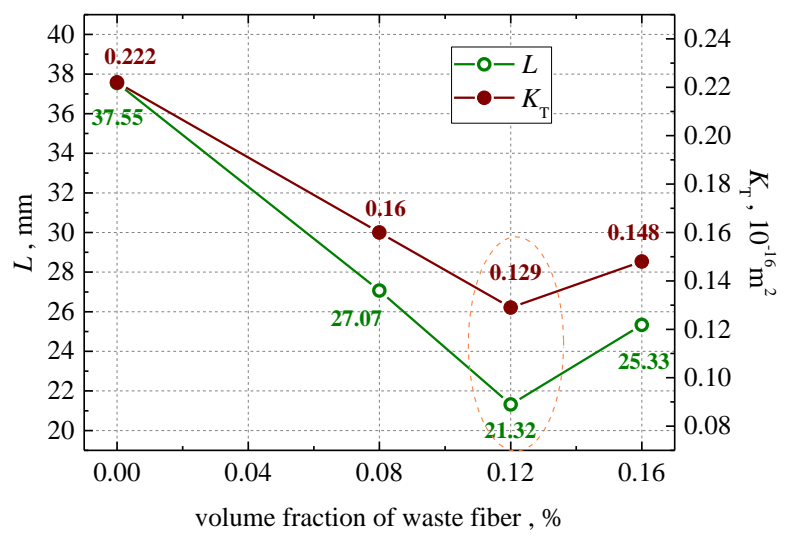

d

Fig. 5. Relationship between $K_{\mathrm{T}}$ and $L$; a-water-cement ratio; $\mathrm{b}$ - replacement rate of recycled aggregates; $\mathrm{c}$ - waste fiber length; $\mathrm{d}$-waste fiber volume content

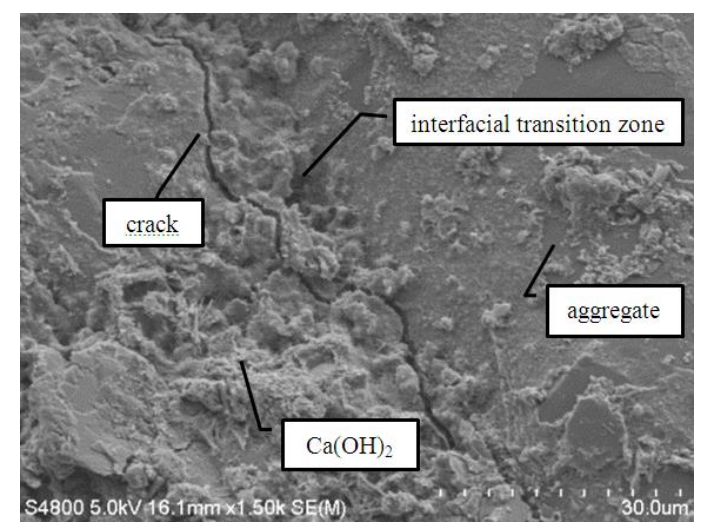

Fig.6. Micro-morphology of recycled concrete

With the increase of fiber length, gas permeability coefficient $K_{T}$ and gas penetration depth $L$ of waste fiber recycled concrete decreased. When fiber length increased from $19 \mathrm{~mm}$ to $30 \mathrm{~mm}$, the rate of decline in gas infiltration parameter slowed down. With the increase of volume fraction of waste fiber, the curves first decreased and then increased (see Fig. 5 d and Fig. 7). In Fig. 7, fibers are wrapped in cement paste, and the addition of fibers can improve the impermeability of recycled fiber reinforced concrete. The main reason is that a large number of waste fibers evenly distributed in recycled concrete can play a role of crack resistance and refine the role of pore structure. It reduces the formation of through cracks and harmful large holes. The proper amount of waste fiber can block up the previously connected capillary pores, so that the airflow is obstructed in the waste fiber recycled concrete matrix, thus improving the impermeability.

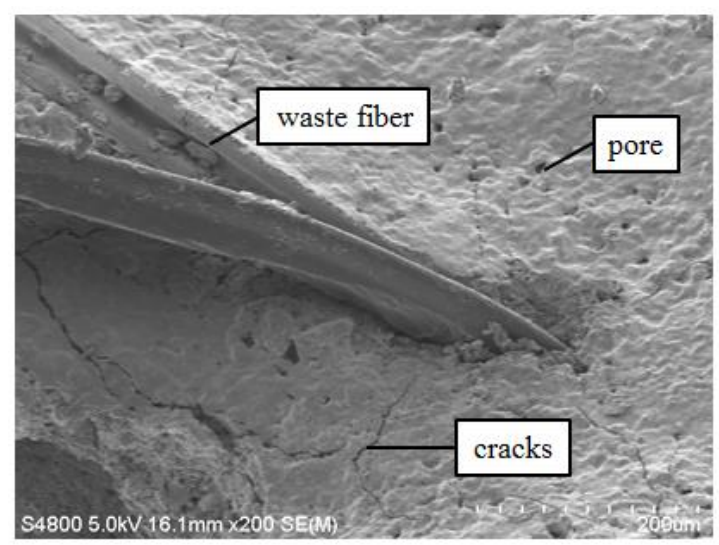

Fig. 7. Micro-morphology of waste fibers

\subsection{The relationship between pore structure and permeability}

The study in section 3.1 showed that the pore volume fractal dimension can be used to characterize the pore structure of waste fiber recycled concrete. Pore volume fractal dimensions and permeability parameters were fitted to study the relationship between pore structure and permeability, and the results are given in Fig. 8 and Fig. 9.

Fig. 8 and Fig. 9 indicate that there is a correlation between pore volume fractal dimension and gas permeability coefficient. The greater the permeability coefficient, the deeper the depth of penetration and the smaller the fractal dimension of the corresponding pore 
volume. The relationship between them can be described as follows

$$
D=-\alpha P_{c}+\beta
$$

where $P_{\mathrm{c}}$ is the permeability parameter; $\alpha$ and $\beta$ are constants and listed in Table 4.

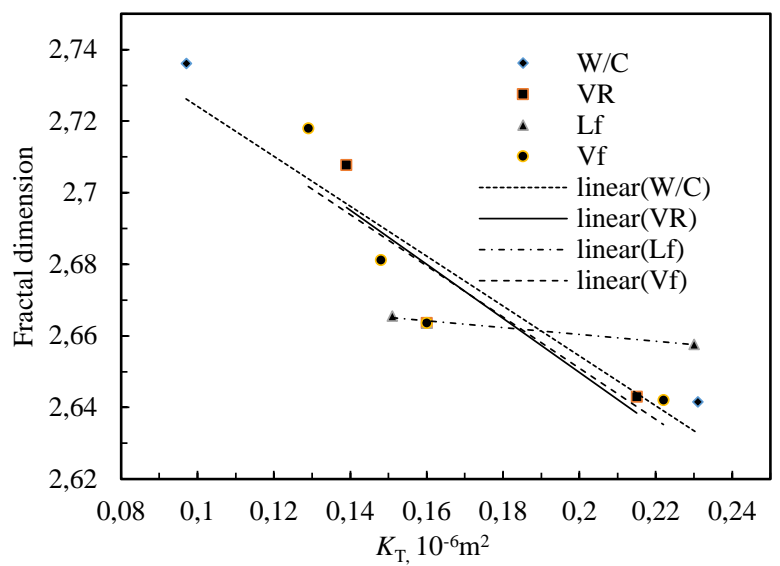

Fig. 8. The relationship between $D$ and $K_{\mathrm{T}}$

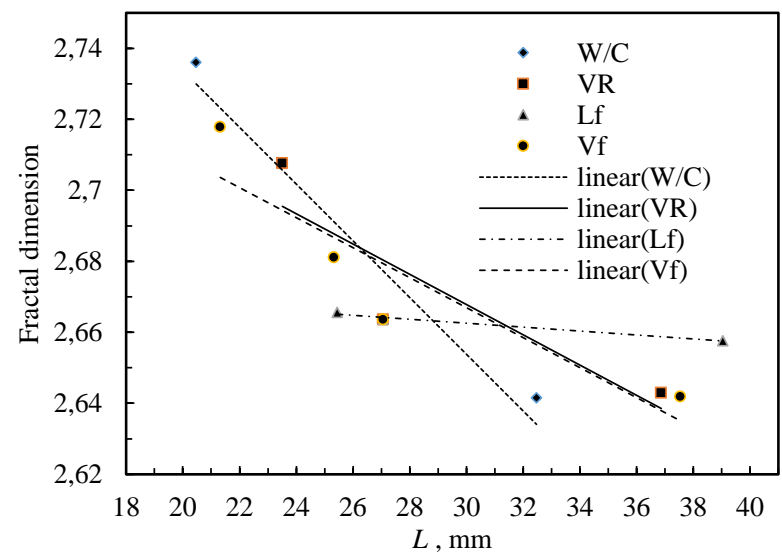

Fig. 9. The relationship between $D$ and $L$

It can be seen from Table 4 that there is a linear relationship between pore volume fractal dimension and parameters of gas permeability coefficient, and the correlation coefficients are greater than 0.9. The fractal dimension of pore volume is closely related to its compactness, and the coarser the concrete structure, the larger the fractal dimension. Therefore, the pore structure of recycled fiber concrete affects the permeability, which is consistent with references $[18,23]$. According to pore volume fractal dimension, the impermeability of waste fiber recycled concrete can be judged intuitively.

\section{CONCLUSIONS}

The addition of waste fibers can improve the pore structure and permeability of recycled concrete to a certain extent. The conclusions from this study provide a reference for further research and application of this type of green recycled concrete. The following conclusions were drawn from this study.

With the increase of water-cement ratio and replacement rate of recycled aggregate, the waste fiber length decreased, and the influence of pore size distribution on permeability $(r \leq 100)$ was reduced. When the volume content of waste fibers is $0.12 \%$, the improvement of pore structure is the most favorable. The volume fraction of waste fiber has a greater effect on the pore structure than the fiber length. The addition of waste fibers can refine the harmful pore to improve the pore structure of the waste fiber recycled concrete.

As the water-cement ratio and recycled aggregate replacement rate increased, so does the permeability of waste fiber recycled concrete. The proper amount of waste fibers can block previously connected capillary pores, so that the airflow is obstructed in the waste fiber recycled concrete matrix, thus improving the impermeability.

The pore volume fractal dimension is between 2 and 3, and it can be used to quantify the complexity of the pore structure. The fractal dimension of waste fiber recycled concrete is linearly related to gas permeability parameter, and the correlation coefficient is above 0.9. The permeability is mainly affected by the pore structure, and the larger the fractal dimension, the lower the permeability.

\section{Acknowledgements}

This work is supported by the fund of Nation Natural Science Foundation of China (Grand No. 51678374). The financial support is gratefully acknowledged.

\section{REFERENCES}

1. Oikonomou, N. Recycled Concrete Aggregates Cement and Concrete Composites 27 (2) 2005: pp. 315-318. https://dx.doi.org/10.1016/j.cemconcomp.2004.02.020

2. Xiao, J.Z., Li, W.G., Fan, Y.H., Huang, X. An Overview of Study on Recycled Aggregate Concrete in China (1996-2011) Construction and Building Materials 31 (6) 2012: pp. $364-383$. https://dx.doi.org/10.1016/j.conbuildmat.2011.12.074

3. Otsuki, N., Miyazato, S., Yodsudjai, W. Influence of Recycled Aggregate on Interfacial Transition Zone, Strength, Chloride Penetration and Carbonation of Concrete Journal of Materials in Civil Engineering 15 (5) 2003: pp. 443-451. https://dx.doi.org/10.1061/(ASCE)0899-1561(2003)15:5 (443)

Table 4. Regression coefficients in Eq. 2

\begin{tabular}{|l|c|c|c|c|c|c|}
\hline \multirow{2}{*}{ Design variables } & \multicolumn{2}{c|}{ Gas permeability coefficient $\left(K_{\mathrm{T}}\right)$} & \multicolumn{3}{c|}{ Gas penetration depth $(L)$} \\
\cline { 2 - 7 } & $\alpha$ & $\beta$ & Correlation R & $\alpha$ & $\beta$ & Correlation R \\
\hline Water-cement ratio (W/C) & 0.6971 & 2.7938 & 0.9451 & 0.0080 & 2.8935 & 0.9711 \\
\hline Replacement ratio of recycled aggregate (VR) & 0.7555 & 2.8009 & 0.9065 & 0.0043 & 2.7957 & 0.9017 \\
\hline Waste fiber length (Lf) & 0.0952 & 2.6795 & 0.9909 & 0.0006 & 2.6792 & 0.9915 \\
\hline Waste fiber volume fraction (Vf) & 0.7150 & 2.7040 & 0.9058 & 0.0042 & 2.7937 & 0.9104 \\
\hline
\end{tabular}


4. Radonjanin, V., $\quad$ Malešev, M., $\quad$ Marinković, S., Malty, A.E.S.A. Green Recycled Aggregate Concrete Construction and Building Materials 47 (5) 2013: pp. $1503-1511$.

https://dx.doi.org/ 10.1016/j.conbuildmat.2013.06.076

5. Poon, C.S., Chan, D. The Use of Recycled Aggregate in Concrete in Hong Kong Resources Conservation and Recycling 50 (3) 2007: pp. 293-305.

https://dx.doi.org/10.1016/j.resconrec.2006.06.005

6. Wang, Y., Wu, H.C., Li, V.C. Concrete Reinforcement with Recycled Fibers Journal of Materials in Civil Engineering 12 (4) 2000: pp. 314-319.

https://dx.doi.org/10.1061/(ASCE)0899-1561(2000)12:4 (314)

7. Carneiro, J.A., Lima, P.R.L., Leite, M.B. Compressive Stress-Strain Behavior of Steel Fiber Reinforced-Recycled Aggregate Concrete Cement and Concrete Composites 46 (4) 2014: pp. 65-72.

http://dx.doi.org/ 10.1016/j.cemconcomp.2013.11.006

8. Amini, F., Bafghi, M.A.B., Safayenikoo, H., Sarkardeh, H., Strength of Different Fiber Reinforced Concrete in Marine Environment Materials Science (Medžiagotyra) 24 (2) 2014: pp. 65-72.

https:// dx.doi.org/ 10.5755/j01.ms.24.2.17909

9. Yin,S., Tuladhar, R., Shanks, R.A., Collister, T., Combe, M., Jacob, M. Fiber Preparation and Mechanical Properties of Recycled Polypropylene for Reinforcing Concrete Journal of Applied Polymer Science 132 (16) 2015: pp. $41866(1-10)$.

https://dx.doi.org/ 10.1002/app.41866

10. Zhou, J.H., Kang, T.B., Wang, F.C. Experimental Study on the Seismic Behaviors of Waste Fiber Recycled Concrete Frame Joints World Information on Earthquake Engineering 36 (2) 2017: pp. 236-242.

https://dx.doi.org/10.13465/j.cnki.jvs.2017.02.038

11. Zhou, J.H., Cheng, L., Dong. W. Waste Fiber Recycled Concrete Performance Based on Fracture Mechanics Research Applied Mechanics and Materials 387 2013: pp. $105-109$.

https://dx.doi.org/10.4028/www.scientific.net/AMM.387.105

12. Wang, Y., Zureick, A.H., Cho, B.S., Scott, D.E., Properties of Fibre Reinforced Concrete Using Recycled Fibres from Carpet Industrial Waste Journal of Materials Science 29 (16) 1994: pp. 4191-4199.

https://dx.doi.org/10.1007/BF00414198

13. Mehta, P.K., Paulo, J.M. Concrete: Microstructure, Properties, and Materials McGraw-Hill Professional 2006: pp. $32-41$.

14. Ollivier, J.P., Massat, M. Permeability and Microstructure of Concrete: A Review of Modeling Cement and Concrete Research $22(2-3)$ 1992: pp. 503-514. https://dx.doi.org/10.1016/0008-8846(92)90094-C

15. Kou, S.C., Poon, C.S. Enhancing the Durability Properties of Concrete Prepared with Coarse Recycled Aggregate Construction and Building Materials 35 (10) 2012: pp. $69-76$.

https://dx.doi.org/10.1016/j.conbuildmat.2012.02.032

16. Kwan, W.H., Ramli, M., Kam, K.J. Influence of the Amount of Recycled Coarse Aggregate in Concrete Design and Durability Properties Construction and Building Materials 26 (1) 2011: pp. 565-573. https://dx.doi.org/10.1016/j.conbuildmat.2011.06.059

17. Evangelista, L., de Brito, J. Durability Performance of Concrete Made with Fine Recycled Concrete Aggregates Cement and Concrete Composites 32 2010: pp. 9-14. https://dx.doi.org/10.1016/j.cemconcomp.2009.09.005
18. Bágel, L., Živica, V. Relationship between Pore Structure and Permeability of Hardened Cement Mortars: on the Choice of Effective Pore Structure Parameter Cement and Concrete Research 27 (8) 1997: pp. 1225 - 1235.

https://dx.doi.org/10.1016/S0008-8846(97)00111-7

19. Wu, Z.W., Lian, H.Z., High Performance Concrete Beijing: Railway Press of China 1999.

20. Basheer, L., Kropp, J., Cleland, D.J. Assessment of the Durability of Concrete from its Permeation Properties: A Review Construction and Building Materials $15(2-3)$ 2001: pp. $93-103$. https://dx.doi.org/10.1016/S0950-0618(00)00058-1

21. Toutianji, H., McNeil, S., Bayasi., Z. Chloride Permeability and Impact Resistance of Polypropylene-Fiber-Reinforced Silica Fume Concrete Cement and Concrete Research 28 (7) 1998: pp. $961-968$. https://dx.doi.org/10.1016/S0008-8846(98)00073-8

22. Zaharieva, R., Buyle-Bodin, F., Skoczylas, F. Assessment of the Surface Permeation Properties of Recycled Aggregate Concrete Cement and Concrete Composites 25 (2) 2003: pp. $223-232$. https://dx.doi.org/10.1016/S0958-9465(02)00010-0

23. Ravindrarajah, R.S., Tam, C.T. Properties of Concrete Made with Crushed Concrete as Coarse Aggregate Magazine of Concrete Research 37 (130) 1985: pp. 29-38. https://dx.doi.org/10.1680/macr.1985.37.130.29

24. Mandelbrot, B.B., Passoja, D.E., Paullay, A.J. Fractal Character of Fracture Surfaces of Metals Nature 308 (5961) 1984: pp. $721-722$. https://dx.doi.org/10.1038/308721a0

25. Prokopski, G., Langier, B. Effect of Water/Cement Ratio and Silica Fume Addition on the Fracture Toughness and Morphology of Fractured Surfaces of Gravel Concretes Cement and Concrete Research 30 (9) 2000: pp. $1427-1433$. https://dx.doi.org/10.1016/S0008-8846(00)00332-X

26. Saouma, V.E., Barton, C.C., Gamaleldin, N.A. Fractal Characterization of Fracture Surfaces in Concrete Engineering Fracture Mechanics 35 (1) 1990: pp. 47-53. https://dx.doi.org/10.1016/0013-7944(90)90182-G

27. Issa, M.A., Islam, M.S., Chudnovsky, A. Fractal Dimension-A Measure of Fracture Roughness and Toughness of Concrete Engineering Fracture Mechanics 70 (1) 2003: pp. $125-137$. https://dx.doi.org/10.1016/S0013-7944(02)00019-X

28. Pape, H., Clauser, C. Permeability Prediction Based on Fractal Pore-Space Geometry Geophysics $64(5)$ 1999: pp. $1447-1460$. https://dx.doi.org/10.1190/1.1444649

29. Abell, A.B. Willis, K.L., Lange, D.A. Mercury Intrusion Porosimetry and Image Analysis of Cement-Based Materials Journal of Colloid and Interface Science 211 (1) 1999: pp. 39-44. http://dx.doi.org/10.1006/jcis.1998.5986

30. Marí, A., Etxeberria, M., Vázquez, E. Microstructure Analysis of Hardened Recycled Aggregate Concrete Magazine of Concrete Research 58 (10) 2006: pp. 683-690. https://dx.doi.org/10.1680/macr.2006.58.10.683

31. Kou, S.C., Poon, C.S. Etxeberria, M. Influence of Recycled Aggregates on Long Term Mechanical Properties and Pore Size Distribution of Concrete Cement and Concrete Composites 33 (2) 2011: pp. 286-291. http://dx.doi.org/10.1016/j.cemconcomp.2010.10.003 
32. Gómez-Soberón, J.M.V. Porosity of Recycled Concrete with Substitution of Recycled Concrete Aggregate: An Experimental Study Cement and Concrete Research 32 (8) 2002: pp. $1301-1311$.

http://dx.doi.org/10.1016/S0008-8846(02)00795-0

33. Ying, J., Zhou, B., Xiao, J. Pore Structure and Chloride Diffusivity of Recycled Aggregate Concrete with nano-SiO 2 , and nano-TiO 2 Construction and Building Materials 150 2017: pp. $49-55$. http://dx.doi.org/10.1016/j.conbuildmat.2017.05.168

34. Guo, Y., Qian, J., Wang., X. Pore Structure and Influence of Recycled Aggregate Concrete on Drying Shrinkage Mathematical Problems in Engineering 2013: pp. 206-226.

http://dx.doi.org/10.1155/2013/912412 